death, in Valkalla, the hall of Odin - the paradise of heroes.

In Saxon England, the characteristic national revels were embalmed in song, for

$$
\begin{aligned}
& \text { "'Tis merry in hall } \\
& \text { When beards wag all"- }
\end{aligned}
$$

a description totally inapplicable to the frantic and insane fury of Celtic intoxication.

The application of some of the principles advanced in this paper is of much wider extent than a superficial consideration of them would indicate. I will confine myself, however, to a single point.

Prof. Wiesmann, of Frieburg, has recently claimed that "characters acquired by the parent are not transmitted to the offspring." There is nothing to show that the national habit of beer. drinking might not have been in entire accord with the barbarous customs and surroundings of the ancient German people. It is not impossible, indeed, but the habit may have been, under the circumstances, conservative and beneficial. But as the manners of the ruder times became softened, and good houses and pleasant homes arose on all sides, while the lights of civilization began also to glow and brighten, the ancient custom of drinking was not correspondingly affected. It was not abated, apparently, in the smallest degree. What was at first, probably, a habit merely circumstantial, became, by long continuance through ages, a habit personal, central, constitutional; and, when the ancient circumstances had disappeared, the hereditary mark, affixed to the constitution of the race, remained unmoved and unchanged. So deeply implanted is the proclivity for malt liquors in the German people, that it is questionable if a portion of the advantages and pleasures of civilization itself would not be surrendered, rather than the national and traditional habit of beerdrinking should be abandoned.

Illustrations of the influence of race on the characteristics of inebriety might be multiplied. The American race, the African race, and many distinctive tribes and families, furnish examples of the fact that the phenomena and responsibilities of drunkenness are modified by constitutional peculiarities. And this truth shows that in estimating the motive and guilt of imputed crime, the utmost circumspection, discrimination and industry should be brought to bear on the investigation. For it shows a weakness in the legal assumption that the criminal inebriate knows, before he drinks, what will be the effect of drunkenness upon the powers of his mind and will.

\footnotetext{
I Journal of Am. Med. Ass'n, I89o, Dec. 27, page 924.
}

TREATMENT OF THE OPIUM NEUROSIS.

Read before the Section of Medical Jurisprudence and Neurology, at the Forty-second Annual Meeting of the American Medical Association, held at Washington, D. C., May, 1891. BY S'EPHEN LETT, M.D.,

MEDICAL SUPERINTENDENT OF THE HOMEWOOD RETREAT, GUELPH, ONT., CANADA.

It is not my intention to enter into elaborate statistics to prove the prevalence of the opium disease, or to discuss the causes which operate in its production; suffice it to say, that the babitual consumption of opium and its products does exist to a very alarming extent in this country, and that some of the causes which give rise to this malady are under our control; others are beyond our power. Nor do I purpose portraying the dire physical and mental manifestations resulting from the daily and prolonged use of the drug, interesting and instructive as the subject might prove to be, but rather do I wish to confine myself to a consideration of the treatment of this disease as it is presented to us, and indicate those methods which, in my hands, have proved most practicable, and, in my opinion, calculated to produce the best results.

In that plan of treatment which I am about to advocate, I cannot lay claim to originality, having closely followed the lines marked out by others in the plan of treatment known as "gradual reduction."

In attempting to treat the opium disease, it is all important the physician should eliminate from the mind the vice theory, and consider the case in the light of a disease, which presents certain pathological conditions requiring skill, patience and sympathy to successfully combat, fully as much as when he is treating other forms of disease.

What the special pathology of this disease is has not been clearly demonstrated; but that such a condition exists can hardly be questioned, and has been strongly insisted upon by eminent au. thority.

When we find a patient able to take repeated poisonous doses of such a drug as opium, with perfect impunity, and when it is demonstrated that such doses are essential to his bodily comfort, or even necessary to sustain life itself, certainly there is the justifiable inference that some change in the animal economy has taken place, that a departure from normal action is set up, and that a pathological condition is established. Dr. Clouston, in the July, I89o, number of the Quarterly Journal of Inebriety, clearly recognizes this diseased condition, while Dr. Charles L. Hughes, of St. Louis, in the Alienist and Neurologist for

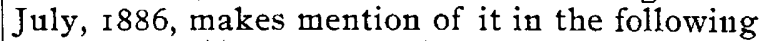
language: "The long continued use of opium or of its salts engenders a disorder of the nervous system which is entitled to distinct recognition. Its sequence is as much a pathological entity as alcoholism, saturnism, hysteria or chorea." 
"Meco-neuro-pathy," he says, "is as much entitled to recognition as that well-known disease, epilepsia."

This assertion he fortifies by many interesting and undisputable facts, and in this connection, draws particular attention to, and points a vividly realistic picture of, the dire results consequent upon the sudden deprivation of the accustomed drug in an opium habituate. Many other eminent men hold the same opinion, and I look forward to no distant date when we shall see these assertions verified by microscopic demonstration.

These pathological changes appear to be situated, chiefly, in the nervous system, more particularly in the great nerve centers, and thus false impressions are conveyed to all organs of the body, thereby interfering with the due performance of their several physiological functions, producing disturbance and discord where harmony and normal action should exist.

Without enquiring further into the pathology of chronic opium poisoning, and accepting as fact that disease does exist, it remains for me to give a résumé of the methods of treatment advocated and adopted.

In the first place, we must bear in mind that there is no drug known to the medical profession which will cure this disease. We have no specific for it. Substitutes there may be, but substitution is not curing the neurosis, and the risk of producing a worse disease thereby requires extreme caution as to the selection of such a remedy.

Three separate and distinct modes of treating the opium habit are advocated and practiced: I. That of abrupt and total withdrawal of the drug; 2 , its rapid reduction; 3 , that of gradual reduction.

As regards the abrupt withdrawal of the drug, I cannot for a moment countenance such a barbarous, inhuman and dangerous procedure, involving, as it does, the most exquisite torture, which no being on earth can fully realize save the opium habituate deprived of his opium. 'The shock to the nervous system is so intense as to make a lasting impression, which is manifested in the higher brain functions, and the risk of fatal collapse is unjustifiable. Words fail me to adequately express the reprehension I would cast upon those who set out on this despotic course, or to convey to you an appreciable idea of the misery and suffering it entails upon a most pitiable and helpless creature. I am astonished beyond measure to find so eminent an authority as Dr. Clouston, of the Royal Edinburgh Asylum, advocating and carrying this treatment into practice. The deservedly recognized marked attainments he possesses, the careful and sound observations he has made and recorded in otber neuropathic disorders, the valuable work on in- sanity he has published - a book which should adorn the library of every asylum physician and the distinguished position he occupies among his confréres, gives weight as coming $e x$ cathedra to anything smanating from his pen. I would not dare to thus criticise his treatment of the morphinomaniac were it not that I feel it a duty to humanity to protest against such cruelties being practiced upon a most unfortunate class of sufferers who are powerless to defend themselves. How a man endowed with the keen accurate perception and high educational attainments of Dr. Clouston, whose long and varied experience among the mentally afflicted must have developed in a marked degree that sympathy for suffering humanity which is so essential to the successful treatment of the insane, could ever advocate, much less carry into practice, such "heroic"' treatment, is to me, at least, a problem incapable of solution.

In his article published in the Quarterly Journal of Inebriety, vol. xii, No. iv, page 3 I I, he clearly recognizes the diseased condition we are now considering, and truly describes in terse language the subject thereof in the following words: "A morphinomaniac, in the advanced stage of his complaint, is a most miserable object in mind and body. He is manifestly diseased in all his nerves and most of his other functions. There is just one other being on earth who is more miserable-looking and more miserable, and that is the morphinomaniac who is being cured by enforced abstinence. The one is alive; the other is more than half dead. As we shall see, the fight is not altogether for the cure of the deadly habit, but in the first instance, to enable the patient to live through the cure."

Such are Dr. Clouston's accurate observations; nevertheless, in the very next paragraph he gives us a sample of his mode of curing this disease by enforced abstinence, which he justly admits causes a fight to keep the patient alive. Look at the pitiable subject he practices this on. A man, in the first instance, weighted down with a "distinct nervous diathesis," who at an early age suffered under a severe illness, which left him weak and sleepless. He "crams" beyond his strength to pass examination at college; buoys himself up on opium; he becomes the subject of rheumatic arthritis at the end of twenty-five years of morphia disease; under compulsion, he places himself as a voluntary patient in an asylum. $\mathrm{He}$ now presents the appearance of a "broken-down looking man," a physical and mental wreck. He was treated with beef-tea and brandy. We are told "the beef-tea caused diarrhcea, and had to be stopped. He could retain milk, liquid custards and brandy better than anything else. The heart's action got very weak, and digitalis seemed to strengthen it. No morphia was given. For a week he was horribly depressed and debil- 
itated, and his life was certainly in danger." Under chloral and bromides, "he slept restlessly and awoke with a feeling of horrors." Contrary to what I would have expected, he weathered the storm and reached anchorage, but what a wreck, to use Dr. Clouston's own words! 'His brain is irretrievably damaged in all its bigher functions by his twenty-five years' continuous intoxication by opium."

How sublimely does the doctor take shelter behind this twenty-five years of so-called "intoxication by opium," and ascribe to this cause all the permanent damage done to the "higher brain functions." Granted that the opium was an important factor in the production of this dire result, did not the fearful ordeal the unfortunate victim went through tend to still further disorganize and produce a marked untoward impression upon an already mentally depressed and physically diseased condition; could the same man, crippled as he was with an originally unstable nervous organization, even tnough he had never tasted an opiate, have gone through a similar ordeal and retained a "mens sana in cupore sano;" would not a milder form of treatment have at least prevented so terrible a shock and given nature a far better chance to repair the inroads made upon the patient's health by the long continued morphia habit? What was there in the result that in the smallest measure compensated for the terrible suffering sustained in effecting a so-called cure. What advantage accrued either to the patient, society or science, by this barbarous treatment? Would it not have been better to have permitted the poor creature to continue his morphia, and in his own way enjoyed what few years were left to him to live, and when death was inevitable have quietly, gently and tenderly lowered him to his grave with as little pain as possible?

Two other cases are recorded by Dr. Clouston in the same article; the same line of treatment was adopted, the same ordeal passed through, similar results obtained. If this is success, if this is a cure. "I will none of it." I have said enough about the abrupt withdrawal plan of treatment. Let us draw a curtain over this horrible picture, hide it from view, and pass from so revolting a topic to the second plan of treatment, that of

\section{RAPID REDUC'TION.}

I regret being unable to speak from experience as to the merits or demerits of the rapid withdrawal plan of treating the opium habituate. Such has not been my practice, therefore what I may say regarding it is gleaned from the literature pertaining thereto, more especially the publications of my friend Dr. Mattison, of Brooklyn, and those of Professor Ball, of the Paris Faculty of Medicine. Both these gentlemen, as well as many others, appear to have met with marked success and satisfactory results. Certainly this method of treatment seems to carry with it many advantages, The time occupied in removing the drug from the circulation is comparatively short, from eight days or less to two or three weeks. yet it is withdrawn by such gradations that the shock to the nervous system is not so great or the danger of collapse so imminent as when the patient is at once deprived of all opiates; at the same time other remedies are employed which appear to have the desirable effect of quieting the nervous system and sustaining the patient whilst the final withdrawal is being accomplished, thereby safely carrying him through a crisis otherwise critical; when this object is attained the special remedies employed are apparently discontinued without inconvenience. A mongst such agents so employed may be enumerated, general and special stimulants, cardiac tonics atd nerve sedatives, such as ether, alcohol, nitro glycerine, sulphate of spartein, the various preparations of valerian, jamaica, dogwood, cannabis indica, belladonna, hyoscine, electricity, hydrocyanic acid, phosphoric acid, paraldehyde, chlora1 and the bromides, especially the bromides of soda in large doses mounting up to $\xi i$ per day. This latter has been especially brought to the notice of the profession by Dr. Mattison, in whose hands it appears to have proved a valuable reme$\mathrm{dy}$, fulfilling a most important office and safely meeting all required indications. As accessories, hot mustard, salt or electric baths, sustaining nourishment, careful nursing, and the best of hygienic surroundings.

As already stated, I have not followed out the treatment by rapid reduction, chiefly because I have found the more gradual method, though involving more time, eminently satisfactory and have thereby safely and successfully cured many patients whose enfeebled condition appeared to me to prohibit the more rapid method. I must also confess being somewhat skeptical as to the ease and freedom from pain with which an opium habituate can be cured by rapid reduction, and before abandoning that mode which I have found satisfactory, I would like more information than I possess as to pain, discomfiture, restlessness and general relaxation of the mucous membranes. Whether in the rapid reduction plan such phenomena are severe or merely trivial in character. Again, it appears to me that the time required to restore the general health and overcome the inroads made upon it by years of opium addiction, is quite equal to the extra time involved by the gradual reduction method. Many writers state that fully six months should be occupied in such restoration, but $I$ know in practice, the rule is a much shorter period spent under special medical supervision. 
GRADUAL, REDUCTION.

It now remains for me to consider the third mode of treatment, viz.: that of gradual reduction, which has been so ably described and advocated by Dr. Hughes, of St. Louis, and practiced by myself and many others. It is claimed to be rational, humane and a safe line of treatment, reassuring to the patient, and what is allimportant, presents to their minds a feasible and comparatively easy mode of casting off these shackles which have so unrelentingly bound them for so many years, constituting them veritable slaves to an overpowering drug which is gradually but surely pressing them onward to meet a miserable and appalling death, which comes at last as a relief to a more pitiful and painful existence.

This treatment essentially consists in a slow, even and methodical withdrawal of the drug, without substitution; at the same time using all the means known to medical science to restore, as far as possible, the shattered nervous system, which is the universal condition of all these cases. The gradual withdrawal of the opiate is effected by decreasing the amount in fractions of a grain at each dose, and the following is a general outline of my mode of procedure.

Having by a categorical enquiry ascertained as nearly as possible, the amount of opiate the patient is in the habit of taking during twentyfour hours, I calculate its equivalent of morphia, then dividing this amount by the number of times it is necessary for him to resort to it during the day, a fair approximate of a simple dose is arrived at. This dose is carefully weighed, administered, and its effects noted; especially as to the following points: Does it sufficiently sustain the patient and keep him comfortable? How long does its effect last? When would a repeti. tion of it be necessary to prevent depression, and would a smaller dose suffice. In a few days by careful observations of this nature, accuracy is obtained, a basis of treatment instituted, and reduction commenced. The rate at which reduction progresses must be governed entirely by the nature of the case in hand. Some patients will bear to be reduced faster than others; much depends upon the physical condition and the quantity of opiate consumed, those taking large quantities can, at the commencement, be reduced faster than where a less amount is the starting point. The guiding ruie is, to remember there 1s a point at which the patient remains comfortable for a certain number of hours. That point can be noted between the extremes of stimulation by excessive opiate and depression consequent upon too small a dose. Upon the accuracy of adjustment of the dose to this point, depends the ease or the discomfiture of the patient, and success in treatment. The rate of reduction also varies with the progress of the case. As a rule, when treatment is commenced with a patient taking, say 20 grains of morphia a day, reduction can be effected at the rate of about one grain every three days. As the quantity taken in twenty-four hours gets less, so also must reduction be more gradual, so that it will require four, five, six or even ten days to withdraw a single grain. When a point is reached at which only one grain is consumed in twenty-four hours the greatest skill, care, and caution is necessary, and to remove this single grain I usually employ from three to four weeks, gradually paring a fractiun of a grain from each dose, and when you remember that that last grain is divided into perhaps three or four doses in the day, the final dose being brought down to so fine a point as ${ }^{6}{ }^{6} \overline{0}$ of a grain, you can appreciate the delicate and gentle manner in which it is withdrawn. No appreciable difference in the dose is noticed by the patient, no shock is produced on the nervous system, the dreaded upsetting of the stomach is avoided; there is little or no relaxation of the mucous membranes, diarrhoa is almost absent, or if present is so mild that the patient will not complain of it. There is no restiveness or inability to continue at a fixed occupation; sleep is usually good, natural and refreshing, and the patient finally slips from under the yoke of the demon opium without being able to note when he took the last dose. Emerging from his years of tyrannical bondage with a new lease of life, buoyant in spirits, physically improved and mentally bright.

Such a course of treatment necessarily involves constant and ever watchful care on the part of the medical attendant, and such physicians who are not prepared to devote time and patience to it had better not set out in the task. To those who follow it out faithfully, the result will amply reward them for all the trouble involved. Each dose should be put up by the physician himself. Accuracy in measurement is essential, none the less so, is punctuality in the time of administration; this cannot be accomplished without some fixed method to work upon. With such method the task is not so insuperable as might at first appear, though I doubt if the general practitioner could carry it out; the uncertainty of his movements would seriously conflict. In order to insure accuracy of dose and steady reduction the method adopted is as follows: When regular treatment is commenced two mixtures are compounded and the bottles labelled respectively $I$ and 2 . No. I is a mixture containing some of the vegetable tonics, with glycerine and water sufficient to form a $3200 \mathrm{mix}-$ ture; to this is added one-half the amount of morphia per $3 \overline{1}$ you wish to give at a dose. No. 2 is precisely the same as No. I minus the morphia; $3 \bar{i}$ are now taken from No. I and admin- 
istered to the patient, the same amount is taken from No. 2 and poured into No. I. The latter will now contain a fraction less morphia per $3 \bar{i}$ than the original mixture, that fraction multiplied by 2 represents the amount of reduction at the next dose. A record of each dose should be accurately kept; it is most important to be able to tell at any moment what the morphia strength of the solution is, as there are times when it is necessary to discontinue the reduction for a few days, or other periods when it is prudent to increase the rate of reduction by removing a certain amount of the mixture from the bottle, or an accident may arise whereby the bottle gets broken or some of the mixture spilt, etc.; under such contingencies, unless the strength of the mixture is absolutely known, it cannot be replenished without interfering with the even tenor of treatment. It is also desirable to know the rate at which reduction is proceeding, and when nearing the end, to be in a position to say that such a dose will be the final one, and be certain a crisis will not follow its withdrawal.

Such a record as $X$ have indicated is easily kept in a case book with suitable rulings for the following headings: Date, time for dose, bulk of mixture, amount of morphia to $3 \bar{i}$, quantity of morphia at each dose, daily amount of morphia, daily reduction, quantity of morphia left in mixture. It is but a minute's simple calculation to place the correct figures in the appropriate columns, and a glance at any time gives you accurate information. The calculations are best worked out in decimals and should be carried to the third decimal place.

Thus I have given you a general detail of the method I adopt, to evenly and methodically re. duce the morphia. Certain modifications are necessary to meet special exigencies. Should reduction be going on too rapidly and signs of depression set up, the patient is easily righted by halting for a few days and holding him at the point reached. It is sometimes astonishing to see how rapidly the system will respond to this rest; in a short time the patient will be bright and buoyant, when, the mixture being replenished, reduction may again be safely resumed, though perhaps at a slackened pace. In some cases many such rests are required. In others reduction may proceed steadily from commencement to finish without inconvenience.

Concurrent with this reducing process our skill must be directed to restoring the physical health and bringing it as nearly as may be to a natural standard. Sustaining nourishment, if necessary repeated at short intervals, frequently a light meal at bed time, is of great advantage. But usually the appetite soon improves and regular meals are enjoyed. Pleasant recreations of a light nature short of fatigue, and out of door exercise should be encouraged. Tonics, chiefly iron and quinine in tonic doses; the syrups of the hypophosphites is an admirable form. Some cases, however, do not bear the strychnine well; when it is tolerated it proves useful. In emaciated cases cod-liver oil emulsion will be found of service.

If from causes you cannot control, time is an important consideration and you are obliged to push the reduction more rapidly than sound judgment would dictate, restlessness and loss of sleep coming on, gr. $1 / 2$ doses cannabis indica ext., will prove a valuable aid. Hot salt baths with friction to the skin is of much value; 3 ss. doses fluid ext. humuli often produces refreshing sle€p, or occasional doses of chloral, paraldehyde or antipyrine at bed time, will be followed by good results. Electricity and stimulating liniments will allay the pains sure to arise if too rapid reduction is practiced. Salsiminum will relieve old neuralgias now likely to give trouble.

All opium patients are more or less troubled with constipation, oftentimes very obstinate. Keep the bowels regulated but do not make a "Balaklava charge" on the alimentary canal by giving drastic purgatives; paralyzed nerves resent such treatment. "Milder measures best prevail." A copious enema will relieve the lower bowel, and lubricate the passage for the discharge of hardened accumulations. A mild mercurial is often of much service. When it is desirable simply to clear the intestinal tract my sheet anchor is fl. ext. cascara sagrada and glycerine in equal parts.

Alcohol in any form I disapprove of, it invariably causes a demand for more morphia. Bromide of potash in sufficient doses to be of any use causes too much after-depression. Cocaine in the treatment of the opium habit I have tried and discarded as dangerous in the extreme.

In cases of double addiction of morphia and alcohol, or morphia and cocaine, I invariably at once withdraw the alcohol or cocaine and continue the morphia, giving sufficiently large doses to keep the patient comfortable. I can fight and conquer one devil but not two.

Whatever form of opiate is used, I follow Dr. Hubbard's recommendation to discard it at once and give its equivalent of morphia. So also with the use of the hypodermic syringe; I abandon that and administer morphia by the mouth. Patients are apt to object to this at first, but they soon realize the many advantages gained by the change. The same dose administered by the mouth will sustain the patient fully as well as when given hy podermically; it is however, less prompt in its action, but more lasting.

With very much broken down and highly nervous patients, I permit them to retain their syringe and morphia until they become accustomed to their surroundings and the new order of affairs; it is a source of much comfort to them, dispels 
their fears and in my experience will not be used unless necessity requires it. In a few days, when confidence is established, the syringe together with all morphia, will be voluntarily handed to me, and the patient will place himself entirely and unreservedly under my care, willing to assist in the treatment of his case to the utmost of his ability.

Lastly, I would enjoin you to pour out your full sympathy towards the unfortunate opium habituate who has had a hard battle to sum up enough courage to present himself to you for treatment. He needs help. He needs care. He needs kindness. He has suffered long years of torture and deprivation; been tossed hither and thither, like a rudderless vessel, upon the turbulent waves of a cold and austere world; looked upon as a vicious outcast whose every action is treated with suspicion, his statements doubted, his case mismanaged. Give credence to what he tells you. Extend a rescuing hand to the drowning man. Pour oil and wine on his smarting wounds, let your full sympathy and aid go out towards him; you will then brighten a dark spot in the deepest of despair, and have the heartfelt thankfulness of an ever grateful fellow being.

\section{DOES SCIENCE JUSTIFY THE USE OF ALCOHOI, IN THERAPEUTICS? IF SO, WHERE? WHEN? \\ Read before the Section of Medical Jurisprudence and Neurology, a the Forty-second Annual Meeting of the American Medical Association, Washington, D. C., May 6, 1897 . \\ BY ELISHA CHENERY, M.D., OF BOSTON, MASS.}

The time is upon the profession to review and recast its notions concerning the use of the alcoholic compounds in the treatment of disease, grounded upon what they are, what they do, and what they do not do; for Argus-eyed science of our day shows alcohol to be widely different from what was supposed of it, in the years that are past. If our fathers drove their cows around a stump to make them give down the milk, we are not bound to do the same. Moreover, the liquor treatment has come to have a moral bearing, which both the human and the divine of our profession requires that we respect. And let me here add what the learned President of this Section has said: "The influence and teaching of the medical profession on the great drink question, is most imperatively demanded." Yet I radically differ from him in another statement: "Medically and scientifically, the whole subject is the polar region of mystery."

Certainly this speaks poorly of the candor of those who still prescribe it. If so, then why not leave it alone?

Bunyan got his hero into the Slough of Despond; but does any one in his senses believe that the Slough of Despond is a necessary part of the pilgrim's pathway?

My subject compares to my time, to day, like a man's hat to a boy's head. Hence I can touch only a few points, and that in the most unsatisfactory way-of leaving out most of the proofs of my positions.

\section{ALCOHOL AS A RESTORATIVE.}

This term includes the tonics-agents which increase strength and overcome languor-the promoters of the constructive metamorphoses, and the force producers. It excludes that which adds nothing, only whips out the strength the body already has. Restoratives are in great demand. The physician to-day prescribes them more frequently than any, if not all, others. $\mathrm{He}$ feels, when doing so, he is adding to the sum total of vitality.

Considering alcohol in this relation, we meet the fact that its chemistry is squarely against it. Not a particle is incorporated into the bodily tissues; so, to say the least, he is visionary in the extreme who prescribes it with the idea that it is incorporated, or that it incorporates anything else.

It contains carbon, as all carbo-hydrate food substances do; but that carbon cannot be extracted from it as from them. They all undergo certain changes, as chemistry shows; while it enters, pervades, and escapes from the body as alcohol, no proof of its transformation, either in the digestive tract, the blood or the tissues, ever having been found. This one fact of its indigestibility nullifies all arguments in its behalf as a force producer. If any contend that it does change, let them give the evidence.

The various symptoms, commonly attributed to this supposed change, are very satisfactorily accounted for from its known irritating and anæsthetic actions. Yet if we admitted all that has been claimed for it in this respect, we concede very little, for Voit and Subbotin say: "In the amount we can take without injury, its importance as a nutriment is too small to be considered." But we have no warrant for the concession.

That all the liquor taken cannot be recovered, we allow. It is the same when alcohol is mingled directly with freshly drawn blood: But the mere loss of a portion is not a proof that that portion changes and becomes useful. Such conclusion is not scientific nor rational. The loss of my knife is not proof that Jones has it, or that he stole it. As well contend that Stanley's "rear column" found Emin Bey. Better do as Hahnemann did-jump from the tangible of medicines into their spirituality. Right reason requires that we withhold our conclusions till we establish the premises. In the light of the foregoing, how unreasonable were the assumptions 